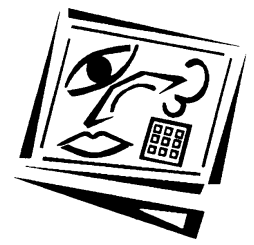

\title{
A matched-pairs study of interactive computer laboratory activities in a liberal arts math course
}

Frederick Butler

York College of Pennsylvania

Melanie Butler

Mount St Mary's University

This paper details the culmination of a large, multi-year study on the effects of an interactive computer laboratory component in a large liberal arts math course at a state university. After several semesters of piloting these laboratory activities in the course, one of two sections, taught by the same senior instructor, was randomly selected to devote approximately one-third of class time to these activities. The other section was used as a control, with the students receiving a lecture on the same material as was explored in the lab activities. Both sections had approximately 220 students. Of these, 42 students from each section of the course were matched on cumulative GPA, math SAT subscore, year in college, and college math background. The pairs were compared via performance on various course components, and on a pre to post assessment designed to measure problem solving abilities. The two course sections were also compared on an inventory of attitudes toward mathematics. The study found that the interactive laboratory activities may provide some benefits to the students, in terms of learning goals and attitudes toward mathematics.

\section{Background}

\section{Description of Liberal Arts Math}

Liberal Arts Math (LAM) is a terminal course at West Virginia University, typically taken by non-science and engineering students. The LAM course fulfills the university's mathematics requirement, but is not a prerequisite for another math course. Typical majors of LAM students include journalism, physical education, English, history, and creative arts. LAM has had its share of challenges in the past, which provided the motivation for research into improving outcomes in the course. LAM is taught in sections of approximately 220 students, with class meetings held in a large lecture hall. The number of students in the class makes it very difficult for the instructor to form personal relationships with more than a few students, while the setting makes it difficult to employ teaching techniques other than lecture in the course. Student backgrounds are such that the majority of students see little use for mathematics, creating a largely negative atmosphere in the classroom. All of these factors combined to result in historical DFW rates (the percentage of students who finish the course with a grade of D or F, or who withdraw from the class) in the 40 to 60 percent range. 
When the first author was hired as the LAM coordinator for West Virginia University in 2004, improving outcomes in the course was a major priority. As such, the LAM coordinator decided to integrate technology into the course in an effort to improve the student experience. More details on how technology is integrated into LAM and other courses at West Virginia University can be found in Butler \& Butler (2006, 2007, 2008a, 2008b) and Butler et al, (2006). All lectures were delivered using PowerPoint. A course website, housed using the WebCT learning management system, enabled students to obtain course information (syllabus, assigned homework problems, etc.), complete most assessments, download PowerPoint slides, and track grades. A personal response system (PRS) and an ID swiping system were used for class participation and attendance. Additionally, course grades were reworked to incorporate multiple forms of assessment, to accommodate students with varied learning styles. Students took four unit exams and a final exam on WebCT. There were ten WebCT homework assignments, completed outside of class. Three attempts were allowed on each homework assignment (with a different random selection of questions on each attempt), and the highest scoring attempt was counted. Attendance and participation were also counted toward the course grade, with three absences allowed before the student lost points.

The central feature of the LAM overhaul, however, was a computer laboratory component. To address the student perception that mathematics was not useful, the LAM coordinator decided the laboratory activities would focus on interesting applications of mathematics. To keep students engaged throughout these lessons, they would be taught using interactive computer laboratory assignments based on the constructivist theory of learning. This approach was generic enough that it could be applied to the wide variety of mathematical areas covered in the course, including set theory, logic, number theory, geometry, probability, and statistics. The labs covered several non-standard mathematics application topics, such as the mathematics behind basic music theory, relating logic to electrical circuits, RSA encryption, and tilings of the plane. The hope was that these activities would improve student attitudes, leading to a better classroom atmosphere, and eventually enhanced student learning in the course. The laboratory component of the course is the subject of this research.

\section{Literature review}

The constructivist approach is a staple of the interactive computer laboratory activities in the LAM course. The authors will use the term constructivism to refer to what Matthews (1997) calls "educational constructivism," a pedagogical philosophy which "...stresses the individual creation of knowledge and construction of concepts," and "... the importance of the group ... for the development and validation of ideas." More information about the use of constructivism in education can be found in Larochelle, Bednarz and Garrison (1998), Tobin (1994), and von Glaserfeld (1989).

There is a substantial body of research supporting the effectiveness of constructivist strategies in the classroom. For example, Lord (1997) reports on a study in which students in a constructivist biology classroom performed better than students taught by the standard approach. A matched pairs study by Witzel, Mercer and Miller (2003) showed that middle school students introduced to the concept of solving algebraic equations through concrete manipulatives outperformed students who received traditional instruction. A study of constructivist-based learning materials in social studies (Karaduman \& Gültekin, 2007) shows that such activities can improve student retention of material. Furthermore, activity based instruction in science class has 
shown to benefit students with learning problems (Cawley \& Cawley, 1994; Mastropieri \& Scruggs, 1992). Another study has shown that knowledge of mathematics concepts is best learned when a student discovers it on his own (Davis, Maher \& Noddings, 1990).

Research has also been conducted on the use of computer resources in constructivist activities. Most studies support the notion that computer based constructivist activities are at least as effective as more traditional ones. Kaput (1992) reports on a research study in which all students learned as well with computer manipulatives as with their hand held counterparts, and some students were more successful with the computer system. Moyer et al (2005) notes that kindergarten students created more complex patterns using web based virtual blocks than traditional wooden blocks. Computer simulations also have the advantage that they may permit explorations which would not be possible using other approaches. For example, Barnett, Yamagata-Lynch, Keating, Barab and Hay (2005) detail how students in an astronomy class create a virtual solar system, modify planetary rotations, and learn how sunrise looks when viewed from the moon.

One major goal of the labs is to use application problems to broaden students' understanding of what mathematics is. These types of problems, Greer (1997) notes, "...may be viewed as the link between the 'two faces' of mathematics, namely its grounding in aspects of reality, and the development of abstract formal structures." Lahme et al (2006) notes it is important to "...present practical problems that help change the students' flawed or narrow views of what mathematics is." The other major goal of the labs is to help students develop quantitative problem solving abilities. Research has shown that inquiry based assignments help to improve students' higher order cognitive skills (Zoller, 1999). Mayer (1999) reviews results from more than 40 studies, concluding that, "multimedia learning environments can promote constructivist learning that, in turn, enables problem-solving transfer."

One of the main purposes of homework is to provide students with formative feedback. A major drawback of traditional paper and pencil homework is that the students receive feedback long after the assignment is completed, as noted by Ponomarenko (2003). In using WebCT for the labs, students are provided with immediate feedback on their performance. Other research on similar lab assignments is reported in Butler (2008). Finally, we note that preliminary results from this research are reported in Butler and Butler (2009).

\section{Research methods}

\section{Research design}

In the Spring 2007 semester, two sections of LAM were offered. Both sections met on Monday and Wednesday at similar times of day (1:00-1:50 pm and 2:00-2:50 pm) for lecture. A third class meeting on Friday, which will henceforth be referred to as an Application Recitation, was the one difference between the sections. It is discussed in more detail in the paragraph below. An attempt was made to give students in each section as similar an experience as possible. Enrollment in both sections was capped at 220. Lectures for the two sections were held in the same campus classroom. The instructor for both sections was the same senior lecturer, who has taught the course numerous times in previous semesters. PowerPoint lectures, written by the first author, were used for lecture in both sections to minimise variability. Students in both sections 
completed essentially identical homework assignments and exams on WebCT, with questions randomly drawn from the same pools. PRS questions were embedded in the PowerPoint slide shows, and thus were exactly the same for the two sections.

Both sections had exactly the same course policies and grade break-down. Students took four unit exams on WebCT, worth $10 \%$ each, and a WebCT final exam worth $20 \%$. There were ten WebCT homework assignments completed outside of class, worth a total of $15 \%$. Three attempts were allowed on each homework (with a different random selection of questions for each attempt), and the highest scoring attempt was counted. Attendance and participation comprised $15 \%$ of the course grade, with three absences allowed before a student lost points. The Application Recitations comprised $10 \%$ of the course grade.

The one manner in which the two sections differed was the format of the Application Recitations. The 2:00 to 2:50 pm section was randomly chosen to be the Control Section in this study. As was mentioned earlier, the Control Section received a traditional lecture on the core material of the course for the first two class meetings a week. During the Friday meeting each week, the students from the Control Section received lectures, also delivered via PowerPoint and written by the first author, on applications of the material. This approach was chosen for the Application Recitations in the Control Section because the authors wanted a comparison to the standard approach to teaching in these large-sectioned classes. These students were given a handout, and asked to fill in blanks on the handout based on information given during lecture. The handouts were very closely aligned with the PowerPoint slides, often made from copies of the slides with words removed. These handouts were then turned in to the instructor and graded for correctness, making up the Application Recitation portion of the course grade for the Control Section.

The 1:00 to 1:50 pm section was the Experimental Section in this study. For the first two class meetings each week these students met with the instructor as a class of 220 in a large lecture hall, just as in the Control Section. During the Friday meeting each week, the students in the Experimental Section were broken into smaller groups of approximately 80 in a computer lab. Instead of receiving lectures on the application material, these students collaborated on laboratory assignments in small groups. The laboratory assignments were strongly based on constructivist principles. Students were guided to develop significant mathematical concepts with minimal direction from the instructor, typically making use of some sort of technology in the process. For example, in the music lab students utilised a piano java applet to recognise mathematical patterns in music, by listening to which combinations of notes sound right to the ear. The tiling lab had students using a tiling java applet, which allowed them to dynamically explore which regular polygons (equilateral triangle, square, regular pentagon, etc.) and combinations of regular polygons could tile the plane. More details about these laboratory assignments can be found in (Butler \& Butler 2008a, 2008b, 2009). The students worked together on these assignments to develop, revise, and test their hypotheses. At the end of each such assignment, an essay question asked students to reflect on the main points of the lab in their own words.

During these lab meetings the instructor was not always present, although several graduate students serving as lab mentors were there to offer assistance. These lab mentors received training prior to the lab sessions, including how to use the technology and how to tie the mathematics topic to the application being demonstrated. In the training, it was strongly emphasised that the mentors were not 
supposed to give answers to the students under any circumstances. The lab assignments were completed using the WebCT learning management system, and were only available to students in the lab (not from a home computer). The essays were graded by a graduate teaching assistant, under the guidance of the first author. Lab questions were parallel to those asked on the application handouts completed in the Control Section.

Throughout the semester, there were 10 of these Application Recitations classes (lectures for the Control Section, and labs for the Experimental Section). In both sections attendance at these Application Recitations was mandatory, as there were no make-ups for missed assignments. To account for students needing to miss class for legitimate reasons, only a student's 8 highest scoring application assignments were counted toward the grade. In fact, any points earned on the remaining 2 application assignments were added into the student's grade as extra credit (to encourage students to attend all 10 Application Recitations if possible).

\section{Participants}

Pairs of students, one each from the Control Section and the Experimental Section, were matched using criteria that the authors expected would affect course performance. Matching took place at the beginning of the semester, hence was blind to student performance on any of the measures used to compare the sections. Since the majority of students in LAM have not taken any previous college math courses, all paired students count LAM as their first college math course. Pairs were also matched using cumulative GPA, math SAT subscore, and year in college (as closely as possible).

There were a total of 42 pairs selected. This was the largest number of pairs with similar characteristics that the authors could match between the sections. Cumulative GPAs ranged from 1.54 to 4.00 , and the difference between the cumulative GPAs in each pair did not exceed 0.30. The summary statistics for the GPA of the Control Section $(M=2.83, S D=0.65)$ and the Experimental Section $(M=2.82, S D=0.64)$ were comparable. SAT math subscores ranged from 360 to 620 . Of the 42 pairs, 25 pairs had no difference in SAT math subscores, 11 pairs had a 10 point difference, and the remaining 6 pairs had a 20 point difference. The summary statistics for the SAT math subscores of the Control Section $(M=482.62, S D=62.82)$ and the Experimental Section $(M=480.95, S D=64.95)$ were also comparable. Both sections had freshman, sophomore, junior, and senior level students. However, the vast majority of students in both sections were freshmen or sophomores. Of the 42 pairs, 22 pairs were in the same year of college, 12 pairs differed by 1 year, 3 pairs differed by 2 years, and 5 pairs differed by 3 years. The specific data for all of the matched pairs can be found in the Appendix.

\section{Measures}

There were several measures used to compare the students in Experimental Section with those in the Control Section. A pre and post assessment, designed to measure general problem solving ability, was administered. It consists of 17 multiple choice questions, covering the topics of set theory, logic, number theory, geometry, probability, and statistics. While the material on the pre and post assessment aligned with the course topics, it is a very broad alignment. Anyone with a background in mathematics that is typically covered in high school, including algebra, geometry, and arithmetic, could solve the problems without having first taken the LAM course. The assessment was written by the authors with input from several other mathematics 
instructors at West Virginia University, and underwent several drafts before being finalised. In order to establish test-retest reliability, the assessment was also given twice to 91 LAM students in a previous semester, with one week separating administrations. Because the instrument was fairly short, correlations were conducted using the total number of items answered correctly. The test-retest correlation coefficient for the assessment was found to be $r=.795, p<.001$.

Student performance on various course components was also compared. Components that were of particular interest include Application Recitation mean score, homework quiz mean score, exam mean score, participation mean score, and course mean score. The sections were also compared via performance on exam questions specifically related material covered in the Application Recitations.

In an effort to triangulate the data, student attitudes toward mathematics were measured using the Attitudes toward Mathematics Inventory (ATMI) of Tapia and Marsh (2002). Students were given a small number of extra credit points to voluntarily complete the ATMI at the end of the semester in which the study was conducted. Inventories were done anonymously using $W e b C T^{\prime}$ 's survey function. A total of 169 students in the Experimental Section and 152 students in the Control Section participated. Because the responses were anonymous, paired students are not compared, but rather the aggregate responses from the Control Section are compared to the responses from the Experimental Section. This inventory was used by permission from the author and it was chosen for its reliability (Tapia \& Marsh, 2002).

\section{Data analysis}

\section{Pre/post assessment performance}

The Control and Experimental Sections were compared using pre and post assessment performance. This assessment is considered to be an important measure by the researchers, as it was designed specifically in an attempt to measure the students' ability to solve applied problems quantitatively. Only 16 of the matched pairs had both students taking both the pre and post assessments, and only these pairs were used in this analysis.

Paired-samples t-tests were conducted on these assessments to determine if there was a significant difference between the sections. There was no significant difference on the pre assessment between the Control Section $(M=8.56, S D=3.60)$ and the Experimental Section $(M=9.63, S D=2.45)$. There was, however, a significant difference between the sections on the post assessment, $t(15)=2.14, p<.05$. In this case, the Experimental Section $(M=10.5, S D=3.29)$ outperformed the Control Section $(M=7.69, S D=3.65)$.

Even though there was no statistically significant difference between the sections on the pre assessment, the Experimental Section still outperformed the Control section on this assessment. Because of this baseline difference between the sections, an analysis of covariance (ANCOVA) was conducted with a one-factor fixed-effect of Section, the pre-assessment as a covariate, and the post assessment as the dependent variable. In the ANCOVA analysis, there was a significant main effect of Section, $F(1,30)=4.22$, $p<.05$, with students in the Experimental Section outperforming those in the Control Section. The adjusted mean score on the post assessment for the Experimental Section was 10.29, and for the Control Section it was 7.90. 


\section{Course component performance}

To determine whether differences existed between Sections on the relevant course components, a series of paired-sample t-tests were conducted on the matched pairs. There was no significant difference between the Sections on any of these course components. See Table 1 for more details.

Table 1: Course components

\begin{tabular}{|l|l|c|l|l|}
\hline \multicolumn{1}{|c|}{ Component } & \multicolumn{1}{|c|}{ Section } & N & Mean & \multicolumn{1}{c|}{ SD } \\
\hline \multirow{2}{*}{ Application Recitation mean score } & Control & 42 & 81.58 & 13.52 \\
\cline { 2 - 5 } & Experimental & 42 & 80.22 & 13.64 \\
\hline \multirow{2}{*}{ Homework Quiz mean score } & Control & 42 & 81.27 & 13.30 \\
\cline { 2 - 5 } & Experimental & 42 & 80.02 & 17.50 \\
\hline \multirow{2}{*}{ Exam mean score } & Control & 42 & 67.92 & 17.74 \\
\cline { 2 - 5 } & Experimental & 42 & 69.05 & 9.81 \\
\hline Participation mean score & Control & 42 & 91.77 & 22.65 \\
\cline { 2 - 5 } & Experimental & 42 & 86.47 & 34.55 \\
\hline Course mean score & Control & 42 & 77.30 & 14.92 \\
\cline { 2 - 5 } & Experimental & 42 & 76.90 & 9.65 \\
\hline
\end{tabular}

\section{Application Recitation related exam question performance}

To determine what effects the dedicated lab time had on retention of lab-specific material, a series of paired-sample $t$-tests were conducted to compare Sections on those exam questions that addressed material covered in the Application Recitations but not in the lectures. Note that students in both sections received instruction on the topics of these questions, only the format of the instruction differed between the two Sections. For exams 1 through 4, there were two questions related solely to the Application Recitations; for the final exam, however, there was only one question related to the Application Recitations. There was a significant difference between the sections on two questions. The first was the logic and circuits question $t(41)=2.29, p<.05$, with the Experimental Section $(M=75.61, S D=43.48)$ outperforming the Control Section $(M=53.66, S D=50.49)$. The second was the encryption question $t(41)=3.54, p<.01$, with the Experimental Section $(M=46.34, S D=50.49)$ outperforming the Control Section $(M=12.20, S D=33.13)$. There was no significant difference between the Sections on any of the remaining lab related exam questions. See Table 2 for more details.

\section{Attitudes toward Mathematics Inventory comparison}

The ATMI contained 40 items, with 29 items worded positively (for example, "Mathematics is a very worthwhile and necessary subject."), and 11 items worded negatively (for example, "Mathematics is one of my most dreaded subjects."). Students selected responses on a 5-point Likert scale, including Strongly disagree, Disagree, Neutral, Agree, Strongly agree. For positively-worded statements, the answers were converted into numerical data, ranging from one to five, with five corresponding to Strongly agree and one corresponding to Strongly disagree. For the negatively-worded statements, these conversions were reversed. In other words, Strongly disagree corresponds to a value of five and Strongly agree corresponds with a value of one. In this way, higher scores point to more positive feelings towards mathematics. 
Table 2: Application Recitation related exam questions

\begin{tabular}{|c|c|c|c|c|c|}
\hline Exam/Question Topic & Section & $\mathrm{N}$ & Mean & SD & $t$ \\
\hline \multirow[t]{2}{*}{ 1/Applications of sets } & Control & 38 & 57.89 & 50.04 & \multirow[t]{2}{*}{0.00} \\
\hline & Experimental & 38 & 57.89 & 50.04 & \\
\hline \multirow[t]{2}{*}{ 1/Music and math } & Control & 38 & 72.34 & 30.08 & \multirow[t]{2}{*}{0.68} \\
\hline & Experimental & 38 & 76.97 & 31.51 & \\
\hline \multirow[t]{2}{*}{ 2/Informal fallacies } & Control & 40 & 65.00 & 48.30 & \multirow[t]{2}{*}{0.50} \\
\hline & Experimental & 40 & 70.00 & 46.41 & \\
\hline \multirow[t]{2}{*}{ 2/ Logic and circuits } & Control & 41 & 53.66 & 50.49 & \multirow[t]{2}{*}{$2.29^{*}$} \\
\hline & Experimental & 41 & 75.61 & 43.48 & \\
\hline \multirow[t]{2}{*}{ 3/Arithmetic sequences } & Control & 41 & 97.56 & 15.62 & \multirow[t]{2}{*}{-1.67} \\
\hline & Experimental & 41 & 87.81 & 33.13 & \\
\hline \multirow[t]{2}{*}{ 3/Encryption } & Control & 41 & 12.20 & 33.13 & \multirow[t]{2}{*}{$3.54^{* *}$} \\
\hline & Experimental & 41 & 46.34 & 50.49 & \\
\hline \multirow[t]{2}{*}{ 4/Metric conversions } & Control & 38 & 23.68 & 43.09 & \multirow[t]{2}{*}{0.72} \\
\hline & Experimental & 38 & 31.58 & 47.11 & \\
\hline \multirow[t]{2}{*}{ 4/Tiling } & Control & 38 & 80.38 & 28.21 & \multirow[t]{2}{*}{-1.31} \\
\hline & Experimental & 38 & 70.23 & 31.73 & \\
\hline \multirow[t]{2}{*}{ 5/Standard deviation } & Control & 38 & 84.21 & 36.95 & \multirow[t]{2}{*}{0.70} \\
\hline & Experimental & 38 & 89.47 & 31.10 & \\
\hline \multirow[t]{2}{*}{ Overall mean } & Control & 33 & 60.68 & 18.42 & \multirow[t]{2}{*}{1.72} \\
\hline & Experimental & 33 & 68.27 & 17.77 & \\
\hline
\end{tabular}

To determine whether differences existed between the sections, a one-way analysis of variance (ANOVA) was conducted for each item. Only two questions yielded significant differences. Question 24, "I have usually enjoyed studying mathematics in school," $F(1,321)=4.771, p<.05$, yielded more positive responses from the Experimental Section $(M=2.60, S D=1.11)$ than from the Control Section $(M=2.33, S D$ $=1.12$ ). Significant differences were also found on Question 36, "I believe studying math helps me with problem solving in other areas," $F(1,321)=5.512, p<.05$, with the Experimental Section $(M=3.33, S D=.95)$ responding more positively to the statement than the Control Section $(M=3.07, S D=1.07)$.

\section{Discussion}

The improvement of student problem solving ability is one of the chief goals of the interactive lab assignments in LAM. The above data analysis, specifically the pairedsample t-tests and ANCOVA comparing the pre and post assessment performance of the two sections, found that students in the Experimental Section outperformed students in the Control Section on the post assessment. This finding suggests that students in the Experimental Section may have improved their problem solving ability more than students in the Control Section, providing some evidence that the computer laboratory activities are meeting one of their major goals.

Analysis also showed that there were no significant differences between the Experimental and Control Section on any of the course components, but this finding requires some comment. In particular, recall that during the Application Recitations in the Control Section, the instructor lectured on application topics using PowerPoint slides, while the students filled out a worksheet regarding the material being discussed. It is worth noting that these PowerPoint slides very closely followed the worksheets, essentially giving the students in the Control Section the answers to the 
worksheet questions during the Application Recitations. This is in contrast with the Application Recitations for the Experimental Section, in which students were not told the answers to any of the lab questions. Instead, these students were guided by the text of the labs, and the lab mentors, to discover the answers on their own. So the students in the Control section, who were told the correct answers, performed at the same level as students in the Experimental Section, who had to find the answers themselves. This suggests at the very least that students can learn the same amount of material when taught using interactive approaches, as compared to more traditional teaching methods such as lectures.

Another notable finding is that the students in the Experimental Section equaled or outperformed the students in the Control Section on exam questions related to the material covered during the Application Recitations. Exams typically took place two to three weeks after the corresponding Application Recitations. This finding seems to suggest that students in the Experimental Section better retained the material over time, at least two to three weeks after being taught it. As noted earlier, previous research by Karaduman and Gültekin (2007) has suggested that constructivist teaching methods may improve student retention of material. This seems to lend some support this theory. In addition, student attitudes toward mathematics may have been positively impacted slightly by their experiences in the Experimental Section, as compared to the Control Section. Once again, there was not a great difference between the sections, but there was a positive effect associated with the Experimental Section.

\section{Conclusion}

Data analysis from this study shows that the students in the Experimental Section did at least as well as, and in some cases better than, the Control Section on all measures. Furthermore, students had the same or more positive attitudes toward mathematics in the Experimental Section than in the Control Section. These findings suggest that the labs have some positive impact on student problem solving ability, retention of material, and feelings toward mathematics, but the evidence could certainly be stronger. More than three years were spent developing the laboratory component of LAM. The computer lab facility used for LAM (and other courses) houses 80 computers, and cost a considerable amount of money to create. It is also an ongoing expense to maintain and staff the facility. Administrators and course designers need to decide if the differences between traditional and constructivist learning settings are significant enough to justify the additional time and expense necessary to implement constructivist learning on such a large scale. This study does demonstrate that teaching students using interactive, constructivist methods does not diminish their learning of the material when compared with teaching using a more traditional lecture method. Furthermore, this constructivist method does not negatively affect feelings toward mathematics.

There are several aspects of this research that could be improved. In particular, the data analysis and conclusions could be enhanced by repeating the study while ensuring a larger number of students take the pre and post assessment. Additionally, matching students on pre assessment scores could allow a more accurate comparison of the post assessment scores and gains in problem solving abilities between the two sections. Giving the ATMI as a pre and post measure, as well as comparing matched pairs on the ATMI, would improve the strength of the findings on affect. Finally, the research could be greatly strengthened by employing a randomised design in place of the matched pairs design. 
Preliminary research is currently being planned to replicate this study on smaller sections of LAM (around 30 students), taking all of the above considerations into account. Further testing and development of a pre and post assessment has taken place, to improve the instrument's validity and reliability. The authors hope that a randomised design can be employed in this future research, since matching from a smaller population of students is often more difficult.

\section{References}

Barnett, M., Yamagata-Lynch, L., Keating, T., Barab, S. \& Hay, K. E. (2005). Using virtual reality computer models to support student understanding of astronomical concepts. Journal of Computers in Mathematics and Science Teaching, 24(4), 333-56.

Butler, F. \& Butler, M. (2008). Developing interactive laboratories in liberal arts math. In S. Misra, R. Revetria, L. Sztandera, M. Iliescu, A. Zaharim \& H. Parsiani (Eds.), Recent Advances in Education and Educational Technology: Proceedings of the 7th WSEAS International Conference on Education and Educational Technology (pp. 24-29). Venice, 21-23 November. [verified 27 Mar 2011] http:/ / www.wseas.us/e-library/conferences/2008/venice/ edu/edu03.pdf

Butler, F. \& Butler, M. (2009). Preliminary results on the effects of interactive computer labs. Journal of Computing Sciences in Colleges, 25(1), 68-74.

Butler, F. \& Butler, M. (2008). Using technology to enhance liberal arts math. Academic Exchange Quarterly, 12(4), 227-231.

Butler, M. (2008) . Computer labs for pre-service teachers. The Journal of Computing Sciences in Colleges, 24(3), 111-117.

Butler, M. \& Butler, F. (2006). Introduction to personal response systems and studies of their use. In J. Parker (Ed.), Proceedings of the Second Annual IASTED International Conference on Education and Technology (pp. 200-205). Calgary, 17-19 July.

Butler, M. \& Butler, F. (2007). Using a sudoku lab to motivate students in an introductory course. Louisiana Association of Teachers of Mathematics Journal, 4(1). [viewed 16 Dec 2009]. http: / / www2.selu.edu/orgs/LATM/Vol4Num1/Sodoku_lab.pdf

Butler, M., Butler, F., Fuller, E., Mayes, R., Mays, M. \& Pyzdrowski, L. (2008). IML - institutional change in lower division mathematics. In W. Troxel \& M. Cutright (Eds.) Exploring the evidence: Campus-wide initiatives in the first college year. The National Resource Center for The First-Year Experience and Students in Transition. University of South Carolina Press.

Cawley, J. \& Cawley, L. (1994). Science education for students with disabilities. Remedial and Special Education, 15, 67-133.

Davis, R., Maher, C. \& Noddings, N. (1990). Constructivist views on the teaching and learning of mathematics: Journal for Research in Mathematics Education Monograph 4. Reston, VA: National Council of Teachers of Mathematics.

Greer, B. (1997). Modelling reality in mathematics classrooms: The case of word problems. Learning and Instruction, 7(4), 293-307.

Karaduman, H. \& Gültekin, M. (2007). The effect of constructivist learning principles based learning materials to students' attitudes, success, and retention in social studies. The Turkish Online Journal of Educational Technology, 6(3), 98-112, 2007.

http: / / www.tojet.net/articles / 6310.pdf 
Kaput, J. (1992). Technology and mathematics education. In D. Grouws (Ed.), Handbook of research on mathematics teaching and learning (p. 528). Macmillan Publishing Company.

Lahme, B., Morris, J. \& Toubassi, E. (2006). The case for labs in precalculus. In N. Hastings (Ed.), A fresh start for collegiate mathematics: Rethinking the courses below calculus (pp. 310-319). Mathematical Association of America.

Larouchelle, M., Bednarz, N. \& Garrison, J. (1998). Constructivism and education. Cambridge University Press.

Lawson, A. (1995). Science teaching and the development of thinking. Wadsworth Publishing Company.

Lord, T. (1997). A comparison between traditional and constructivist teaching in college biology. Innovative Higher Education, 21(3), 197-216.

Mastropieri, M. \& Scruggs, T. (1992). Science and students with disabilities. Review of Educational Research, 62, 377-411.

Matthews, M. R. (1997). Introductory comments on philosophy and constructivism in science education. Science and Education, 6(1-2), 5-14.

Mayer, R. (1999). Multimedia aids to problem solving transfer. International Journal of Educational Research, 31(7), 611-623.

Moyer, P. S., Niezgoda, D. \& Stanley, J. (2005). Young children's use of virtual manipulatives and other forms of mathematical representations. In W. Masalaski \& P. Elliott (Eds.), Technology-supported mathematics learning environments (pp. 17-34). National Council of Teachers of Mathematics.

Ponomarenko, V. (2003). Drill 3.1. Journal of Online Mathematics and Its Applications, 4. http: / / mathdl.maa.org / mathDL / 4/ ?pa=content\&sa=viewDocument\&nodeId=492 [viewed 17 Dec 2009, verified 29 Mar 2011].

Tapia, M. \& Marsh, G. (2002), Confirmatory factor analysis of the attitudes toward mathematics inventory. Paper presented at the Annual Meeting of the Mid-South Educational Research Association (Chattanooga, TN, November 6-8, 2002). http: / / www.eric.ed.gov:80/ERICWebPortal/ contentdelivery/servlet/ERICServlet?accno=E D471301

Tobin, K. (Ed.) (1993). The practice of constructivism in science education. Washington, DC: American Association for the Advancement of Science Press.

Von Glaserfeld, E. (1989). Constructivism in education. In T. Husen \& N. Postlethwaite (Eds.), The international encyclopedia of education, Supplement Vol. 1 (pp. 162-163). New York: Pergamon Press.

Witzel, B. S., Mercer, C. D. \& Miller, M. D. (2003). Teaching algebra to students with learning difficulties: An investigation of an explicit instruction model. Learning Disabilities: Research $\mathcal{E}$ Practice, 18(2), 121-131.

Zoller, U. (1999). Scaling-up of higher-order cognitive skills-oriented college chemistry teaching: An action-oriented research. Journal of Research in Science Teaching, 36(5), 583-596. 


\section{Appendix}

Table 3: Matched pairs data

FR - freshman (1st yr), SO - sophomore (2nd yr), JR - junior (3rd yr), SR - senior (4th yr)

\begin{tabular}{|c|c|c|c|c|c|c|}
\hline Pair & $\begin{array}{c}\text { Experimental } \\
\text { GPA }\end{array}$ & $\begin{array}{c}\text { Control } \\
\text { GPA }\end{array}$ & $\begin{array}{c}\text { Experimental } \\
\text { SAT }\end{array}$ & $\begin{array}{l}\text { Control } \\
\text { SAT }\end{array}$ & $\begin{array}{c}\text { Experimental } \\
\text { Year }\end{array}$ & $\begin{array}{c}\text { Control } \\
\text { Year }\end{array}$ \\
\hline 1 & 2.75 & 2.96 & 0360 & 0360 & $\mathrm{SO}$ & SR \\
\hline 2 & 2.03 & 2.26 & 0370 & 0370 & $\mathrm{SO}$ & $\mathrm{SO}$ \\
\hline 3 & 3.04 & 3.09 & 0390 & 0410 & FR & SR \\
\hline 4 & 1.54 & 1.52 & 0390 & 0390 & FR & FR \\
\hline 5 & 3.77 & 3.79 & 0420 & 0400 & FR & FR \\
\hline 6 & 2.60 & 2.40 & 0410 & 0410 & FR & FR \\
\hline 7 & 2.84 & 2.77 & 0410 & 0430 & FR & $\mathrm{SO}$ \\
\hline 8 & 2.91 & 2.80 & 0420 & 0440 & SR & $\mathrm{SO}$ \\
\hline 9 & 2.25 & 2.18 & 0420 & 0420 & $\mathrm{SO}$ & $\mathrm{SO}$ \\
\hline 10 & 2.20 & 2.22 & 0420 & 0440 & $\mathrm{SO}$ & JR \\
\hline 11 & 2.83 & 2.53 & 0440 & 0440 & FR & $\mathrm{SO}$ \\
\hline 12 & 2.68 & 2.38 & 0440 & 0440 & $\mathrm{SO}$ & FR \\
\hline 13 & 1.78 & 1.86 & 0440 & 0450 & FR & FR \\
\hline 14 & 4.00 & 3.77 & 0440 & 0450 & FR & FR \\
\hline 15 & 3.07 & 3.37 & 0440 & 0450 & FR & $\mathrm{SO}$ \\
\hline 16 & 2.71 & 2.73 & 0450 & 0450 & $\mathrm{SO}$ & FR \\
\hline 17 & 3.00 & 2.92 & 0460 & 0460 & FR & SR \\
\hline 18 & 3.25 & 3.14 & 0460 & 0470 & FR & FR \\
\hline 19 & 2.18 & 2.16 & 0470 & 0460 & $\mathrm{SO}$ & $\mathrm{SO}$ \\
\hline 20 & 3.48 & 3.44 & 0470 & 0470 & $\mathrm{SO}$ & FR \\
\hline 21 & 3.47 & 3.67 & 0470 & 0480 & FR & FR \\
\hline 22 & 1.67 & 1.94 & 0470 & 0470 & FR & FR \\
\hline 23 & 3.79 & 4.00 & 0480 & 0470 & SR & FR \\
\hline 24 & 2.77 & 2.93 & 0480 & 0470 & FR & $\mathrm{SO}$ \\
\hline 25 & 3.79 & 3.89 & 0490 & 0490 & FR & JR \\
\hline 26 & 2.76 & 2.50 & 0490 & 0490 & JR & SO \\
\hline 27 & 3.27 & 3.21 & 0500 & 0500 & FR & FR \\
\hline 28 & 3.18 & 3.14 & 0510 & 0510 & FR & FR \\
\hline 29 & 2.38 & 2.23 & 0510 & 0510 & FR & FR \\
\hline 30 & 3.06 & 2.93 & 0520 & 0520 & FR & $\mathrm{SO}$ \\
\hline 31 & 2.02 & 2.20 & 0530 & 0530 & $\mathrm{SO}$ & $\mathrm{SO}$ \\
\hline 32 & 1.85 & 1.82 & 0530 & 0530 & $\mathrm{SO}$ & FR \\
\hline 33 & 3.54 & 3.62 & 0540 & 0530 & FR & SR \\
\hline 34 & 2.86 & 2.78 & 0540 & 0540 & $\mathrm{SO}$ & FR \\
\hline 35 & 3.42 & 3.38 & 0560 & 0560 & $\mathrm{SO}$ & $\mathrm{SO}$ \\
\hline 36 & 2.35 & 2.41 & 0550 & 0550 & FR & FR \\
\hline 37 & 1.93 & 2.06 & 0560 & 0560 & FR & FR \\
\hline 38 & 3.22 & 3.18 & 0570 & 0570 & FR & FR \\
\hline 39 & 3.71 & 4.00 & 0580 & 0590 & SR & FR \\
\hline 40 & 2.26 & 2.36 & 0580 & 0590 & FR & FR \\
\hline 41 & 2.75 & 3.00 & 0600 & 0600 & FR & FR \\
\hline 42 & 3.35 & 3.33 & 0620 & 0600 & FR & FR \\
\hline
\end{tabular}

Authors: Dr Frederick M. Butler, Department of Physical Sciences, York College of Pennsylvania, 441 Country Club Road York, PA 17403-3651, USA.

Email: fbutler@ycp.edu Web: http: / / www.ycp.edu/

Dr Melanie Butler, Department of Mathematics, Mount St Mary's University, 16300 Old Emmitsburg Road, Emmitsburg, MD 21727, USA.

Email: mbutler@msmary.edu Web: http://www.msmary.edu /

Please cite as: Butler, F. M. \& Butler, M. (2011). A matched-pairs study of interactive computer laboratory activities in a liberal arts math course. Australasian Journal of Educational Technology, 27(2), 192-203. http:/ / www.ascilite.org.au/ajet/ajet27/ butler.html 